\title{
Solid-state Fermentation on Poplar Sawdust and Corncob Wastes for Lignocellulolytic Enzymes by Different Pleurotus ostreatus Strains
}

\author{
Mei-Ling Han, ${ }^{\text {a,c }}$ Qi An,, a,b,* Sai-Fei He, ${ }^{\text {a }}$ Xiao-Lin Zhang, ${ }^{a}$ Ming-Hui Zhang, ${ }^{\mathrm{a}}$ \\ Xin-Hua Gao, ${ }^{a}$ Qian $\mathrm{Wu},{ }^{a}$ and Lu-Sen Bian ${ }^{\mathrm{d}}$
}

\begin{abstract}
Solid state fermentation with different lignocellulolytic materials as inducers was used for lignocellulolytic enzyme production in this study. Pleurotus ostreatus strains were assessed by measuring laccase, CMCase, and xylanase activities. The secretion potential of the lignocellulolytic enzymes by wild and cultivated strains was analyzed for the first time. The wild and cultivated strain showed their unique capacities for secreting lignocellulolytic enzymes on solid-state fermentation with different lignocellulosic materials. The wild $P$. ostreatus strain preferred corncob for the secretion of laccase and xylanase activity, but the cultivated strain preferred poplar sawdust. The wild strain and cultivated strain showed a consistent preference for poplar sawdust for the secretion of CMCase activity. The wild strain was advantageous because it achieved the maximum hydrolytic enzyme activities within a short time period. Poplar sawdust and corncob were conducive to laccase secretion by the wild or cultivated strains and the rapid accumulation of laccase on solidstate fermentation. Additionally, continuous, stable laccase production was an extremely important advantage by solid-state fermentation of poplar sawdust, particularly in the wild strain. These findings are helpful in selecting the appropriate strain that corresponds to suitable lignocellulosic materials. The optimization of integrated industrial lignocellulolytic enzyme production can also be achieved.
\end{abstract}

Keywords: Pleurotus ostreatus; Corncob; Poplar wood; Wild and cultivated strains; Lignocellulolytic enzymes

Contact information: a: College of Life Science, Langfang Normal University, Langfang 065000, Hebei, China; b: Technical Innovation Center for Utilization of Edible and Medicinal Fungi in Hebei Province, Langfang 065000, Hebei, China; : Edible and Medicinal Fungi Research and Development Center of Universities/Colleges in Hebei Province, Langfang 065000, Hebei, China; d: Experimental Centre of Forestry in North China, Chinese Academy of Forestry, Beijing 102300, China;

* Corresponding author: fungiqian@yahoo.com

\section{INTRODUCTION}

Lignocellulosic biomass, the most abundant and renewable eco-friendly resource on earth, has attracted attention for producing bioenergy and other value-added industrial products (Pinar et al. 2017). Due to the rapid development of agriculture and forestry, huge amounts of biomass waste are produced. Based on dry weight, the annual global primary production of biomass is about 220 billion tons (Chandra et al. 2012; Saratale et al. 2017). In addition, rational use of biomass is also conducive to solving the problem of environmental pollution because of the prohibited burning of agricultural and forestry waste. The production of corn was about 257 million tons in China, and the planting area of poplar exceeded 7 million ha. Corn and poplar related wastes have very little to no 
economic value. They are quite abundant and have become heavily under-valued resources in China. One major product obtained from the bioconversion of lignocellulosic biomass is bioethanol. The process of converting lignocellulosic biomass to bioethanol is facilitated by hydrolytic enzymes. Another major way lignocellulosic biomass is used is to produce edible and medicinal fungi. Edible and medicinal white rot fungi can utilize a variety of lignocellulosic residues by producing several extracellular secreted enzymes. These enzymes grow fruiting bodies for human consumption. Therefore, cultivation of edible fungi on corn and poplar byproducts may be one of the possible solutions for converting these agricultural and forestry wastes into accepted edible food of high and useful market value (Xie et al. 2017). Additionally, there is also a process of producing lignocellulolytic enzymes by solid fermentation.

Pleurotus ostreatus (Jacq.) P. Kumm., an edible basidiomycete, is both a white rot fungus and an edible fungus. $P$. ostreatus grows on lignocellulosic biomass and is one of the well-known producers of lignocellulolytic enzymes (Knežević et al. 2013; An et al. 2016b). All basidiomycetes belonging to the genus Pleurotus can secrete extracellular hydrolytic and oxidative enzymes. These enzymes relate to the degradation of lignocellulose with different efficiencies (Reddy et al. 2003; Elisashvili et al. 2006; Kachlishvili et al. 2006). Lignocellulolytic enzymes contain two groups: the ligninolytic enzymes and the cellulolytic enzymes. The ligninolytic enzymes contain peroxidases and oxidases, while the cellulolytic enzymes contain cellulases and hemicellulases (An et al. 2016b; Nguyen et al. 2018). Lignocellulolytic enzymes are highly specific, safe, and efficient biocatalysts that are exploited in different industrial processes (Asgher et al. 2016). They carry importance and have vast applications in many fields, especially in the area of industry and environmental protection. Utilizing low-cost biological residues from agriculture and forestry as substrates for growing microorganisms may constitute an interesting alternative in the enzyme industry (Lamia et al. 2017).

Many factors affect the secretion of lignocellulolytic enzyme production by fungi, such as the fermentation method, the type and complexity of carbon and nitrogen sources, ion concentration, temperature, and more (Stajić et al. 2006; Sohail et al. 2009; Zhang et al. 2013; Bentil et al. 2018; Ferraz et al. 2019; Filipe et al. 2019; Akpinar and Urek 2020; Rajavat et al. 2020). The types of substrates and the mode of cultivation of fungal species play an essential role in enzyme productivity. These factors also affect the resulting enzyme activity profile (Elisashvili et al. 2008a). The influences of co-cultivation (Metreveli et al. 2017), nutrient medium (An et al. 2016b), and ion type (Saparrat et al. 2010) also have been investigated. Compared to submerged fermentation $(\mathrm{SmF})$, solid-state fermentation (SSF) is a procedure in which the substrate barely appears in water (Nguyen et al. 2019). The low moisture content in the fermentation of microorganisms is limited primarily to yeasts, fungi, and bacteria (Acharya et al. 2010). Fungi are highly adaptable to SSF because the fungal hyphae features are spread across the surface. They easily penetrate inter-particle spaces where their colonization is typically more efficient than other organisms in solid substrates (Sukumaran et al. 2005; Nguyen et al. 2019). More importantly, using solid state fermentation can help avoid the dilution of enzyme products due to the high content of water in submerged fermentation (Oostra et al. 2000).

The production of laccase using an alkaline lignin inducer is different in cultivated and wild strains of $P$. ostreatus (An et al. 2018). However, the effects of different lignocellulosic materials on hydrolytic enzyme production in cultivated and wild strains have not been reported in fungi, particularly in white rot fungi. This study aimed to measure the effects of different lignocellulosic materials on lignocellulolytic enzymes production 
in P. ostreatus and lay a foundation for selecting lignocellulosic materials suitable for different strains producing lignocellulolytic enzymes. This was accomplished using cultivated and wild strains tested in the conventional solid-state fermentation method.

\section{EXPERIMENTAL}

\section{Materials}

Two white-rot fungal strains, one cultivated strain P. ostreatus CCEF99 and one wild strain CY568, were obtained from the Institute of Microbiology, Beijing Forestry University (Beijing, China). All organisms were maintained on a Complete Yeast Medium (CYM) agar medium (glucose $20 \mathrm{~g}$ per L, peptone $2 \mathrm{~g}$ per L, yeast extract $2 \mathrm{~g}$ per L, $\mathrm{MgSO}_{4} \cdot 7 \mathrm{H}_{2} \mathrm{O} 0.5 \mathrm{~g}$ per L, $\mathrm{K}_{2} \mathrm{HPO}_{4} \cdot 3 \mathrm{H}_{2} \mathrm{O} 1 \mathrm{~g}$ per $\mathrm{L}, \mathrm{KH}_{2} \mathrm{PO}_{4} 0.46 \mathrm{~g}$ per L, and agar $20 \mathrm{~g}$ per L) at $4{ }^{\circ} \mathrm{C}$ in the College of Life Science, Langfang Normal University.

Poplar wood and corncob were collected from Langfang Normal University (Hebei, China) and farmers in Chengde city, Hebei province, China. All biomass was chopped into small pieces. All residues were air-dried and ground. The particles of size 20 to 80 -mesh were prepared for subsequent use.

\section{Methods}

Organism and inoculum preparation

The microorganism was transferred to new CYM agar medium plates and incubated at $26{ }^{\circ} \mathrm{C}$ for 7 days. Inoculants with a diameter of $5 \mathrm{~mm}$ were then made on a flat plate covered with mycelium by a hole punch. Under aseptic conditions, 6 inoculants were placed in $250 \mathrm{~mL}$ flasks containing $100 \mathrm{~mL}$ of the CYM medium (glucose $20 \mathrm{~g}$ per L, peptone $2 \mathrm{~g}$ per L, yeast extract $2 \mathrm{~g}$ per $\mathrm{L}, \mathrm{MgSO}_{4} \cdot 7 \mathrm{H}_{2} \mathrm{O} 0.5 \mathrm{~g}$ per $\mathrm{L}, \mathrm{K}_{2} \mathrm{HPO}_{4} \cdot 3 \mathrm{H}_{2} \mathrm{O} 1 \mathrm{~g}$ per $\mathrm{L}$, and $\mathrm{KH}_{2} \mathrm{PO}_{4} 0.46 \mathrm{~g}$ per $\mathrm{L}$ ). The medium was then cultured on a rotary shaker (ZHICHENG, Shanghai, China) at $26{ }^{\circ} \mathrm{C}$ with a speed of $150 \mathrm{rpm}$. After 7 days, mycelial pellets were harvested and homogenized with a laboratory blender (Tianjin hengao Technology Development Co., Ltd, Tianjin, China) for $2 \mathrm{~min}$ at $5000 \mathrm{rpm}$. The resulting suspension was used as an inoculum.

\section{Culture conditions}

The solid-state fermentation (SSF) of the poplar sawdust and corncob was performed individually at $26^{\circ} \mathrm{C}$ in $250 \mathrm{~mL}$ flasks. The flasks contained $3 \mathrm{~g}$ of the substrate and were also moistened with $12 \mathrm{~mL}$ of basal medium (glucose $15 \mathrm{~g}$ per L, yeast extract 6 g per L). All flasks were autoclaved at $121^{\circ} \mathrm{C}$ for $30 \mathrm{~min}$. After being cooled, $3 \mathrm{~mL}$ of the homogenized mycelium was used to inoculate every flask containing the substrate that was moistened with the basal medium. All flasks were incubated at $26{ }^{\circ} \mathrm{C}$.

To determine the enzymes activities under different substrate and strain conditions, the laccase activities were tested on which fungi grew from day 1 to day 10 , day 15, day 20 , day 25, day 30, and day 35. CMCase and xylanase activities were tested on day 5, day 10 , day 15 , day 20 , day 25 , day 30 , and day 35 of the fungi growth. The extracellular enzymes were extracted with $50 \mathrm{mM}$ sodium acetate buffer (pH 5.5). Briefly, $100 \mathrm{~mL}$ of the sodium acetate buffer mentioned above was added into SSF flasks for the extraction process. The extractions were performed on a rotary shaker at $10{ }^{\circ} \mathrm{C}$ with a speed of 150 rpm for $5 \mathrm{~h}$ (An et al. 2016b). The extracted liquid was filtered by Whatman No. 1 filter paper, then centrifuged at $4{ }^{\circ} \mathrm{C}$ with a speed of $12,000 \mathrm{rpm}$ for $20 \mathrm{~min}$. The supernatant 
was the crude enzyme liquid, which was used for measuring the enzyme activity.

\section{Enzyme activities assays}

The laccase (EC 1.10.3.2) activity was determined by the changes in the absorbance at $415 \mathrm{~nm}$, related to the rate of oxidation of $1 \mathrm{mM} \mathrm{2,2'-azinobis-[3-ethyltiazoline-6-}$ sulfonate] (ABTS) in a $50 \mathrm{mM}$ sodium acetate buffer $(\mathrm{pH} \mathrm{4.2)}$. The assay mixture was measured using an iMark $^{\mathrm{TM}}$ Microplate Absorbance Reader (Bio-Rad, Hercules, CA, USA). One unit of enzyme activity was defined as the amount of enzyme required to oxidize $1 \mu \mathrm{mol}$ of ABTS per minute $\left(\varepsilon_{415}=3.16 \times 10^{4} \mathrm{M}^{-1} \mathrm{~cm}^{-1}\right)$.

The endoglucanase (CMCase) activity was determined in accordance with previously described methods (Ghose 1987). Briefly, $0.5 \mathrm{~mL}$ of the appropriately diluted enzyme was extracted with $1.5 \mathrm{~mL}$ of $1 \% \mathrm{w}$ per $\mathrm{v}$ carboxymethyl cellulose, which dissolved in a sodium citrate buffer $(50 \mathrm{mM}, \mathrm{pH} \mathrm{5.0})$ at $40{ }^{\circ} \mathrm{C}$ for $30 \mathrm{~min}$. The reaction was terminated by adding $3 \mathrm{~mL}$ of 3,5-dinitrosalicylic acid reagent and boiled for $10 \mathrm{~min}$. The xylanase activity was determined in accordance with previously described methods (Bailey et al. 1992). The process was like the CMCase method. The absorption was $540 \mathrm{~nm}$. One unit of endoglucanase or xylanase activity was defined as the amount of enzyme releasing $1 \mu \mathrm{mol}$ of reducing sugar per minute under the assay conditions.

All measurements were derived from three independent experiments and the mean values were taken. The standard deviations for the experiments were less than $\pm 10 \%$.

\section{Statistical analysis}

To examine the effects of substrates and strains on laccase, CMCase, and xylanase activities, a two-way analysis of variance followed by the Tukey post hoc test was applied to these variables. The substrates and strains were the fixed factors (PROC GLM, IBM SPSS software version 22.0; Armonk, NY, USA). All statistical figures were generated using the Origin Pro 8.0 program (OriginLab Corporation, Northampton, MA, USA).

\section{RESULTS AND DISCUSSION}

\section{The Effects of Strains and Substrates on the Production of Laccase Enzymes}

Many studies indicate that the particle size, concentration, type, and nature of substrates used as inducer show a notable effect on laccase production (Han et al. 2017, 2018; Leite et al. 2019). Similarly, laccase production is also significantly affected by different species or different strains that belong to the same species ( $\mathrm{p}$-value $<0.001$ ) (Janusz et al. 2015; An et al. 2016a, 2018; Huang et al. 2019). As shown in Table 1, the effect that the substrates have on the laccase activities of $P$. ostreatus was significant most of the time (p-value < 0.05), except on day 5. Meanwhile, the effect of the strains on the laccase activities of $P$. ostreatus was also significant most of the time (p-value $<0.05$ ), except on day 3, day 8, and day 25 .

Obviously, the CY568 wild strain and the CCEF99 cultivated strain showed their unique capacities for secreting laccases on solid-state fermentation with different lignocellulosic material (Fig. 1). The laccase production trend for the CY568 wild strain was different under the substrates of sawdust and corncob. The laccase activity for the CY568 wild strain under sawdust fermentation and corncob fermentation conditions ranged from $36.77 \pm 2.17 \mathrm{U} / \mathrm{L}$ to $353.83 \pm 11.94 \mathrm{U} / \mathrm{L}$ and $9.64 \pm 0.52 \mathrm{U} / \mathrm{L}$ to $440.73 \pm 8.36$ 
U/L, respectively (Fig. 1). The maximum laccase activity for the CY568 wild strain obtained from the corncob substrate was higher than that obtained from the sawdust substrate (approximately 1.25-fold as seen in Table 2).

Table 1. Effects of Strains, Substrates, and Strains $\times$ Substrates Interactions on the Laccase Activities of Pleurotus ostreatus (Two-Way ANOVA)

\begin{tabular}{|c|c|c|c|}
\hline Incubation Period (d) & Strain & Substrate & Strain $\times$ substrate \\
\hline 1 & $276.898^{\star \star *}$ & $872.222^{\star \star \star}$ & $60.469^{* \star *}$ \\
\hline 2 & $346.975^{\star * *}$ & $108.649^{\star \star \star}$ & $18.787^{\star \star}$ \\
\hline 3 & 4.140 & $13.766^{\star *}$ & $11.169^{*}$ \\
\hline 4 & $7.261^{*}$ & $27.830^{\star \star \star \star}$ & $56.657^{\star * \star}$ \\
\hline 5 & $68.426^{\star \star \star}$ & 0.894 & $10.005^{\star}$ \\
\hline 6 & $62.684^{* * *}$ & $6.239^{*}$ & $42.173^{\star * *}$ \\
\hline 7 & $577.230^{* * *}$ & $343.197^{* * *}$ & $162.031^{* * *}$ \\
\hline 8 & 0.344 & $1172.586^{\star \star \star *}$ & $220.569^{\star * \star}$ \\
\hline 9 & $98.218^{* * *}$ & $752.755^{\star \star \star}$ & $956.274^{* \star *}$ \\
\hline 10 & $86.547^{* * *}$ & $528.421^{* \star *}$ & 0 \\
\hline 15 & $203.222^{\star * \star}$ & $2207.150^{\star \star \star}$ & $686.116^{* * *}$ \\
\hline 20 & $9.824^{*}$ & $486.024^{* * *}$ & $47.810^{\star * *}$ \\
\hline 25 & 2.068 & $550.832^{* * *}$ & $42.880^{* * *}$ \\
\hline 30 & $354.384^{* * *}$ & $2234.061^{* * *}$ & $85.313^{* * *}$ \\
\hline 35 & $10.715^{*}$ & $575.145^{\star \star \star}$ & $91.759^{\star * \star}$ \\
\hline
\end{tabular}

The maximum laccase activity for the CY568 strain from sawdust was on day 5, and that of the corncob was on day 7. According to Fig. 1, the laccase activity of the CY568 strain was high and stable from the beginning to day 35 in the presence of sawdust. However, in corncob the laccase activity of the CY568 strain was higher in the early stage and decreased in the later stage. At 35 days, it was only $17.08 \pm 1.06 \mathrm{U} / \mathrm{L}$ from the corncob fermentation, which was about $1 / 7$ of the laccase activity from the sawdust fermentation. The laccase production trend for the CCEF99 cultivated strain was similar under the sawdust and corncob substrates. The laccase activity for the CCEF99 cultivated strain under sawdust fermentation and corncob fermentation conditions ranged from $67.21 \pm 3.67$ $\mathrm{U} / \mathrm{L}$ to $548.72 \pm 19.59 \mathrm{U} / \mathrm{L}$ and $16.88 \pm 1.51 \mathrm{U} / \mathrm{L}$ to $286.12 \pm 25.80 \mathrm{U} / \mathrm{L}$, respectively (Fig. 1). The maximum laccase activity for the CCEF99 cultivated strain obtained from the sawdust substrate was higher than that obtained from the corncob substrate (approximately 1.92-fold as can be seen in Table 2). This was distinguished from the CY568 wild strain. The maximum laccase activity for the CCEF99 strain from the sawdust was on day 9, and that of the corncob was on day 5 (Table 2). The laccase activity of the CCEF99 strain was high and relatively stable from the beginning to day 35 when sawdust was used as the inducer (Fig. 1). The result was similar to the laccase activity from the CY568 strain under the sawdust fermentation. On the other hand, the laccase activity from the CCEF99 strain under fermentation with corncob was relatively low and unstable. Overall, the laccase production of the CCEF99 cultivated strain on poplar sawdust was more efficient than that of the CY568 wild strain. In other words, the CCEF99 cultivated strain showed higher laccase production than the CY568 wild strain when poplar sawdust moistened with a basal 
medium was used as the inducer on the solid-state fermentation. However, the wild $P$. ostreatus strain showed higher laccase activity than the cultivated $P$. ostreatus strain when only alkaline lignin or poplar sawdust was used as the inducer in submerged fermentation. The advantage is relatively obvious (An et al. 2018). It seemed the results were opposite, while this phenomenon was understandable. A possible reason was that the cultivated strains were all domesticated. The domesticated edible fungi grew better on the related cultivated substrates, such as sawdust and cottonseed hull. On the corncob substrate, the laccase production of the CY568 wild strain was higher than that of the CCEF99 cultivated strain. The dominant strains on the two substrates were just the opposite. To some extent, it also reflected the selective specificity of the strain to the substrate.

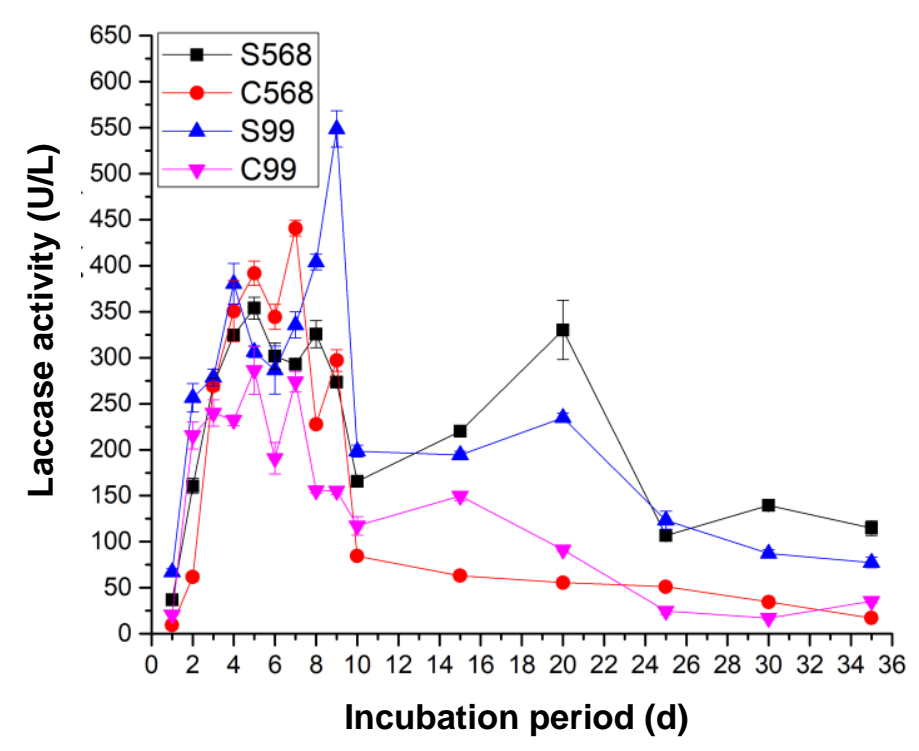

Fig. 1. The effects of different strains and substrates on the laccase production by Pleurotus ostreatus. The average values were calculated from individual measurements for each of the three parallel cultures of the two strains. S568 indicates poplar sawdust with a wild $P$. ostreatus strain CY568; C568 indicates corncob with a wild $P$. ostreatus strain CY568; S99 indicates poplar sawdust with a cultivated $P$. ostreatus strain CCEF99; and C99 indicates corncob with a cultivated $P$. ostreatus strain CCEF99.

Table 2. Maximum Laccase Activities, Lignocellulosic Material, Strains, and the Time of Pleurotus ostreatus Strains

\begin{tabular}{|c|c|c|c|}
\hline $\begin{array}{l}\text { Maximum Laccase Activity } \\
(\mathrm{U} / \mathrm{L})\end{array}$ & Lignocellulosic Material & Strain & Time (day) \\
\hline $353.83 \pm 11.94$ & Poplar sawdust & CY568 & 5 \\
\hline $548.72 \pm 19.60$ & Poplar sawdust & CCEF99 & 9 \\
\hline $440.73 \pm 8.36$ & Corncob & CY568 & 7 \\
\hline $286.12 \pm 25.80$ & Corncob & CCEF99 & 5 \\
\hline
\end{tabular}

The presence of poplar wood is conducive to secreting laccase by P. ostreatus strains in submerged fermentation, but this is a slow process for accumulating laccase (An et al. 2018). Similar to a previous study, poplar sawdust could promote the laccase production of wild or cultivated strain on solid state fermentation, as found in this study. 
Additionally, continuous and stable laccase production was found to be an extremely important advantage by solid-state fermentation of poplar sawdust. This was previously a nonexistent phenomenon of wild or cultivated $P$. ostreatus strains in liquid fermentation. The maximum laccase activity with a lignin-rich walnut shell as the inducer by Funalia trogii is higher than with corncob as the inducer on solid-state fermentation (Birhanli and Yeşilada 2013). The maximum laccase activity with a powdered walnut shell as the inducer by $F$. trogii or Trametes versicolor is higher than with powdered wheat straw as the inducer in submerged fermentation (Birhanli and Yeşilada 2013). The maximum laccase activities secreted by $P$. ostreatus strains used corncob and complete yeast media as the inducer are higher than using sawdust and complete yeast media as the inducer in submerged fermentation (Han et al. 2017). The laccase activity in tree leaves solid-state fermentation by $P$. ostreatus 2175, P. ostreatus IBB8, P. ostreatus IBB108, and P. ostreatus 2191 is 15 U per flask, $7 \mathrm{U}$ per flask, $14 \mathrm{U}$ per flask, and $14 \mathrm{U}$ per flask, respectively (Elisashvili et al. 2008b). The laccase activity in wheat straw solid-state fermentation by $P$. ostreatus 2175, P. ostreatus IBB8, P. ostreatus IBB108, and P. ostreatus 2191 is $12 \mathrm{U}$ per flask, 7 U per flask, $10 \mathrm{U}$ per flask, and $17 \mathrm{U}$ per flask, respectively (Elisashvili et al. 2008b). Additionally, the lignin content of leaves and wheat straw varied greatly from $0 \%$ and 16 to $21 \%$, respectively (Sánchez 2009). The laccase activity in tree leaves solid-state fermentation or in wheat straw solid-state fermentation by P. ostreatus 2175 , P. ostreatus IBB8, P. ostreatus IBB108, and P. ostreatus 2191 has almost no difference (Elisashvili et al. 2008b). All the above studies indicate that the lignin content is not directly proportional to the laccase production secreted of fungi induced by these lignocellulosic materials. A roughly similar phenomenon was also found in this study. The lignin content of corncobs and hardwood stems was $15 \%$ and 18 to $25 \%$ (Sánchez 2009). The laccase activity on the corncob substrate was sometimes higher than on the sawdust substrate (Fig. 1).

\section{The Effects of Strains and Substrates on the Production of CMCase Enzymes}

Cellulase is a generic name for the group of enzymes that catalyze the hydrolysis in cellulose. It is a class of an inducible enzymes produced by organisms, especially fungi. These enzymes can either be free or grouped into a multienzyme complex. The cellulase enzyme system mainly involves three components: endo- $\beta-1,4$-glucanase (EC 3.2.1.4), exo- $\beta-1$, 4-glucanase (EC 3.2.1.91), and $\beta$-glucosidase (EC 3.2.1.21) (Zhang et al. 2006). Fewer articles have considered the effects of wild strains and cultivated strains on cellulose production. Thus, in this research a comparative study of endoglucanase production by wild and cultivated $P$. ostreatus strain on different lignocellulose materials was conducted.

The results demonstrated that the CMCase activities of the two P. ostreatus strains were significantly different $(\mathrm{P}<0.001)$, except on day 15 (Table 3$)$. Various lignocellulose substrates remarkably affected the CMCase activities of different $P$. ostreatus strains $(\mathrm{P}<$ 0.001 ), except on day 5,10 , and 25 (Table 3 ). The extracellular CMCase activity varied from $19.16 \pm 0.32 \mathrm{U} / \mathrm{L}$ to $35.52 \pm 2.79 \mathrm{U} / \mathrm{L}$ and $13.03 \pm 0.32 \mathrm{U} / \mathrm{L}$ to $24.93 \pm 0.56 \mathrm{U} / \mathrm{L}$ by P. ostreatus CY568 on poplar sawdust and corncob, respectively (Fig. 2). The corresponding maximum CMCase activity appeared on days 5 and 10 (Table 4). However, the CCEF89 strain was different from the CY568 strain. The difference was mainly reflected in the maximum enzyme activity and occurrence time. The extracellular CMCase activity varied from $7.27 \pm 0 \mathrm{U} / \mathrm{L}$ to $45.16 \pm 4.65 \mathrm{U} / \mathrm{L}$ and $5.98 \pm 0.32 \mathrm{U} / \mathrm{L}$ to $32.76 \pm 0.49$ U/L by $P$. ostreatus CCEF99 on poplar sawdust and corncob, respectively (Fig. 2). The corresponding maximum CMCase activity appeared on days 30 and 35 (Table 4). In terms of the maximum CMCase activity, the CCEF99 cultivated strain showed superiority to the 
CY568 wild strain. In terms of the time of maximum CMCase activity, the CY568 wild strain performed higher than the CCEF99 cultivated strain (Table 4). On the other hand, the maximum CMCase activity and occurrence time of the two strains were higher on the poplar sawdust solid-state fermentation than on the corncob. Fungi cultivation in identical culture conditions reveal wide differences among both species and strains of the same species (Elisashvili et al. 2008b). In this respect, our results agreed with data of other authors reporting on the quantitative variations of the CMCase activity during solid state cultivation of $P$. ostreatus strains (Reddy et al. 2003; Elisashvili et al. 2008b; Membrillo et al. 2008; An et al. 2016b).

Table 3. Effects of Strains, Substrates, and Strains $\times$ Substrates Interactions on the CMCase Activities of Pleurotus ostreatus (Two-Way ANOVA)

\begin{tabular}{|c|c|c|c|}
\hline Incubation Period (d) & Strain & Substrate & Strain $\times$ substrate \\
\hline 5 & $52.296^{\star \star \star}$ & 0.024 & $574.903^{* * *}$ \\
\hline 10 & $152.893^{* \star \star}$ & 4.794 & $102.037^{\star \star \star}$ \\
\hline 15 & 1.757 & $711.345^{\star * \star}$ & 0.224 \\
\hline 20 & $64.424^{* * *}$ & $300.017^{* * *}$ & 1.729 \\
\hline 25 & $27.453^{* * *}$ & 0.788 & $13.712^{* *}$ \\
\hline 30 & $61.316^{\star \star *}$ & $43.648^{* * *}$ & $24.212^{\star *}$ \\
\hline 35 & $205.714^{* \star *}$ & $173.145^{\star \star \star}$ & $47.424^{* * *}$ \\
\hline
\end{tabular}

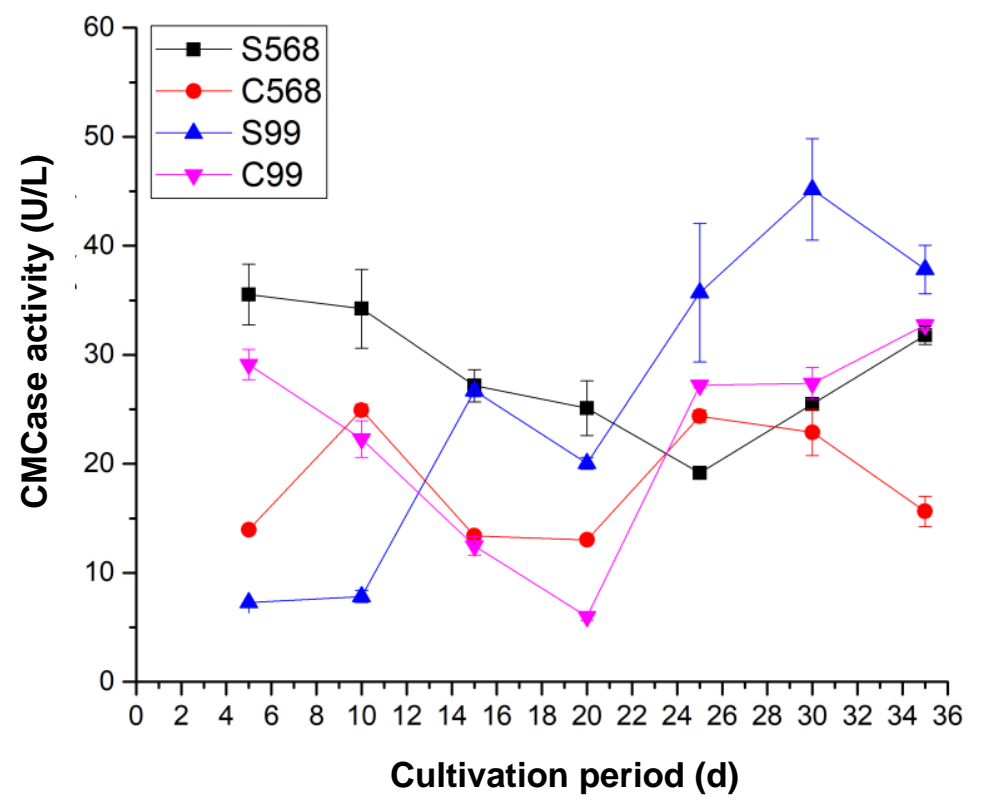

Fig. 2. The effects of different strains and substrates on CMCase production by Pleurotus ostreatus. The average values were calculated from individual measurements for each of the three parallel cultures of the two strains. S568 indicates poplar sawdust with a wild $P$. ostreatus strain CY568, C568 indicates corncob with a wild P. ostreatus strain CY568, S99 indicates poplar sawdust with a cultivated $P$. ostreatus strain CCEF99, and C99 indicates corncob with a cultivated P. ostreatus strain CCEF99. 
Table 4. Maximum CMCase Activities, Lignocellulosic Material, Strains, and the Time of Pleurotus ostreatus Strains

\begin{tabular}{|c|c|c|c|}
\hline $\begin{array}{c}\text { Maximum CMCase Activity } \\
(\mathrm{U} / \mathrm{L})\end{array}$ & Lignocellulosic Material & Strain & Time (day) \\
\hline $35.52 \pm 2.79$ & Poplar sawdust & CY568 & 5 th \\
\hline $45.16 \pm 4.65$ & Poplar sawdust & CCEF99 & 30 th \\
\hline $24.93 \pm 0.56$ & Corncob & CY568 & 10 th \\
\hline $32.76 \pm 0.49$ & Corncob & CCEF99 & 35 th \\
\hline
\end{tabular}

\section{The Effects of Strains and Substrates on the Production of Xylanase Enzymes}

Although similar enzymes are involved for cellulose and hemicellulose biodegradation, more enzymes are required for the complete degradation of hemicellulose because of its greater heterogeneity (Malherbe and Cloete 2002). Hemicelluloses are biodegraded to monomeric sugars and acetic acid. Xylan is the main carbohydrate found in hemicellulose (Sánchez 2009). Complete degradation of xylan requires the cooperative action of a variety of hydrolytic enzymes. Hemicellulases are frequently classified according to their action on distinct substrates. Endo-1,4- $\beta$-xylanase (EC 3.2.1.8) generates oligosaccharides from the cleavage of xylan and xylan-1,4- $\beta$-xylosidase (EC 3.2.1.37) produces xylose from the oligosaccharides (Sánchez 2009). In this research, xylanase activities produced by the wild and cultivated $P$. ostreatus strains were used to compare the performance of different lignocellulose materials.

The effect of strain on xylanase activities of $P$. ostreatus was significant in the early days of cultivation before day 25 (p-value $<0.01$ ). Meanwhile, the effect of the lignocellulose material on xylanase activities of $P$. ostreatus was less significant most of the time (p-value >0.05) (Table 5). Two P. ostreatus strains maintained a higher xylanase activity than the CMCase activity in the detection stage (Fig. 3). The xylanase activity of the CY568 strain on day 5 in the poplar sawdust and corncob substrates were at approximately equivalent levels of $1279.59 \pm 15.19 \mathrm{U} / \mathrm{L}$ and $1263.17 \pm 27.76 \mathrm{U} / \mathrm{L}$, respectively. Similarly, the xylanase activity of the CCEF99 strain was also approximately equivalent in both the poplar sawdust and corncob substrates on day 5 at $1110.22 \pm 40.25$ $\mathrm{U} / \mathrm{L}$ and $1113.22 \pm 110.8 \mathrm{U} / \mathrm{L}$, respectively.

Previous research showed that the xylanase activity of $P$. ostreatus IBB 108 from tree leaves and wheat straw solid-state fermentation was approximately equivalent, about $220 \pm 19$ U/flask and $260 \pm 20$ U/flask (Elisashvili et al. 2008b). That was similar to our results. Interestingly, two strains showed distinct trends in their xylanase activities. However, for one strain the trend of xylanase activity was similar on different lignocellulose materials. The maximum xylanase activity of the CY568 strain was 1324.74 $\pm 46.31 \mathrm{U} / \mathrm{L}$ and $1339.11 \pm 18.73 \mathrm{U} / \mathrm{L}$ on the poplar sawdust and corncob substrates on day 10 (Table 6). After the maximum xylanase activity, the trend of xylanase activity decreased and then increased (Fig. 3). The maximum xylanase activity of the CCEF99 strain on the poplar sawdust and corncob substrates was $1362.53 \pm 66.52 \mathrm{U} / \mathrm{L}$ and $1305.68 \pm 30.70 \mathrm{U} / \mathrm{L}$ on day 35 and 25 , respectively (Table 6). 
Table 5. Effects of Strains, Substrates, and Strains $\times$ Substrates Interactions on the Xylanase Activities of Pleurotus ostreatus (Two-Way ANOVA)

\begin{tabular}{|c|c|c|c|}
\hline Incubation Period $(\mathrm{d})$ & Strain & Substrate & Strain $\times$ substrate \\
\hline 5 & $20.529^{\star *}$ & 0.036 & 0.076 \\
\hline 10 & $101.428^{\star * *}$ & 0.186 & 0.107 \\
\hline 15 & $71.176^{\star \star *}$ & $7.330^{*}$ & 0.021 \\
\hline 20 & $37.799^{\star \star *}$ & $11.822^{\star *}$ & 0.370 \\
\hline 25 & 0.380 & 3.450 & 3.450 \\
\hline 30 & 1.073 & 0.366 & 1.378 \\
\hline 35 & 0.612 & $14.579^{* *}$ & $14.579^{* *}$ \\
\hline
\end{tabular}

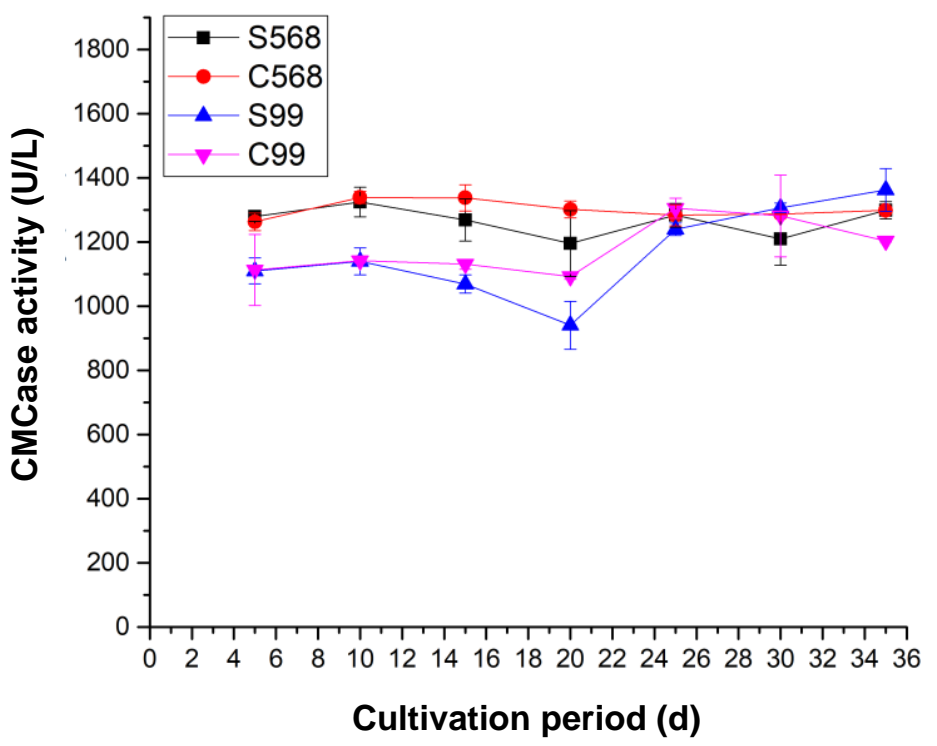

Fig. 3. The effects of different strains and substrates on the xylanase production by Pleurotus ostreatus. The average values were calculated from individual measurements for each of the three parallel cultures of the two strains. S568 indicates poplar sawdust with a wild $P$. ostreatus strain CY568, C568 indicates corncob with a wild $P$. ostreatus strain CY568, S99 indicates poplar sawdust with a cultivated $P$. ostreatus strain CCEF99, and C99 indicates corncob with a cultivated P. ostreatus strain CCEF99.

Table 6. Maximum Xylanase Activities, Lignocellulosic Material, Strains, and the Time of Pleurotus ostreatus Strains

\begin{tabular}{|c|c|c|c|}
\hline $\begin{array}{c}\text { Maximum Xylanase Activity } \\
(\mathrm{U} / \mathrm{L})\end{array}$ & Lignocellulosic material & Strain & Time (day) \\
\hline $1324.74 \pm 46.31$ & Poplar sawdust & CY568 & 10 \\
\hline $1362.53 \pm 66.52$ & Poplar sawdust & CCEF99 & 35 \\
\hline $1339.11 \pm 18.73$ & Corncob & CY568 & 10 \\
\hline $1305.68 \pm 30.70$ & Corncob & CCEF99 & 25 \\
\hline
\end{tabular}




\section{CONCLUSIONS}

1. This study indicated that the biosynthetic potential of basidiomycetes could be highly dependent on the type of fungal and type of lignocellulosic substrate. The preference of wild strain and cultivated strain to lignocellulosic biomass was different.

2. In terms of the laccase and xylanase activity of $P$. ostreatus, the wild strain preferred corncob and the cultivated strain preferred poplar sawdust. The wild strain and cultivated strain showed a consistent preference to poplar sawdust for the secretion of CMCase activity.

3. The wild $P$. ostreatus strain showed exceptional potential for hydrolytic enzyme synthesis through solid-state fermentation with poplar sawdust or corncob as the inducer. The main advantage was that the wild strain could reach the maximum hydrolytic enzyme activities in both substrates within a short period of time.

4. The presence of poplar sawdust and corncob was conducive to secreting laccase by the wild or cultivated $P$. ostreatus strain on solid-state fermentation. Furthermore, it was a fast process for accumulating laccase. Additionally, the continuous and stable laccase production was an extremely important advantage by solid-state fermentation of poplar sawdust. This phenomenon was evident in the case of the wild strain.

\section{ACKNOWLEDGMENTS}

This research was supported by the National Natural Science Foundation of China (31700024), Science Technology Research and Guidance Project of Colleges and Universities in Hebei Province (Z2019001), and the Top-notch Youth Project of Colleges and Universities in Hebei Province (BJ2019007).

\section{REFERENCES CITED}

Acharya, B. K., Mohana, S., Jog, R., Divecha, J., and Madamwar, D. (2010). "Utilization of anaerobically treated distillery spent wash for production of cellulases under solidstate fermentation," J. Environ. Manage. 91, 2019-2027. DOI: 10.1016/j.jenvman.2010.05.001

Akpinar, M., and Urek, R. O. (2020). "Decolorization and degradation potential of enhanced lignocellulolytic enzymes production by Pleurotus eryngii using cherry waste from industry," Biotechnol. Appl. Bioc. (Accepted). DOI: 10.1002/bab.1846

An, Q., Han, M. L., Wu, X. J., Si, J., Cui, B. K., Dai, Y. C., and Wu, B. (2016a). "Laccase production among medicinal mushrooms from the Genus Flammulina (Agaricomycetes) under different treatments in submerged fermentation," Int. J. Med. Mushrooms 18(11), 1049-1059. DOI: 10.1615/IntJMedMushrooms.v18.i11.90

An, Q., Ma, H. F., Han, M. L., Si, J., and Dai, Y. C. (2018). "Effects of different induction media as inducers on laccase activities of Pleurotus ostreatus strains in submerged fermentation," BioResources 13(1), 1143-1156. DOI: 10.15376/biores.13.1.1143-1156

An, Q., Wu, X. J., Han, M. L., Cui, B. K., He, S. H., Dai, Y. C., and Si, J. (2016b). 
"Sequential solid-state and submerged cultivation of white rot fungus Pleurotus ostreatus on lignocellulosic biomass for the activity of lignocellulolytic enzymes," BioResources 11(4), 8791-8805. DOI: 10.15376/biores.11.4.8791-8805

Asgher, M., Ramzan, M., and Bilal, M. (2016). "Purification and characterization of manganese peroxidases from native and mutant Trametes versicolor IBL-04," Chinese J. Catal. 37(4), 561-570. DOI: 10.1016/S1872-2067(15)61044-0

Bailey, M. J., Biely, P., and Poutanen, K. (1992). "Interlaboratory testing of methods for assay of xylanase activity," J. Biotechnol. 23(3), 257-270. DOI: 10.1016/01681656(92)90074-J

Bentil, J. A., Thygesen, A., Mensah, M., Lange, L., and Meyer, A. S. (2018). "Cellulase production by white-rot basidiomycetous fungi: solid-state versus submerged cultivation," Appl. Microbiol. Biot. 102(14), 5827-5839. DOI: 10.1007/s00253-0189072-8

Birhanli, E., and Yeşilada, Ö. (2013). "The utilization of lignocellulosic wastes for laccase production under semisolid-state and submerged fermentation conditions," Turk. J. Biol. 37(4), 450-456. DOI: 10.3906/biy-1211-25

Chandra, R., Takeuchi, H., and Hasegawa, T. (2012). "Methane production from lignocellulosic agricultural crop wastes: A review in context to second generation of biofuel production," Renew. Sust. Energ. Rev. 16(3), 1462-1476. DOI:

10.1016/j.rser.2011.11.035

Elisashvili, V., Penninckx, M., Kachlishvili, E., Asatiani, M., and Kvesitadze, G. (2006). "Use of Pleurotus dryinus for lignocellulolytic enzymes production in submerged fermentation of mandarin peels and tree leaves," Enzyme Microb. Tech. 38(7), 9981004. DOI: 10.1016/j.enzmictec.2005.08.033

Elisashvili, V., Kachlishvili, E., and Penninckx, M. (2008a). "Effect of growth substrate, method of fermentation, and nitrogen source on lignocellulose-degrading enzymes production by white-rot basidiomycetes," J. Ind. Microbiol. Biotechnol. 35, 15311538. DOI: $10.1007 / \mathrm{s} 10295-008-0454-2$

Elisashvili, V., Penninckx, M., Kachlishvili, E., Tsiklauri, N., Metreveli, E., Kharziani, T., and Kvesitadze, G. (2008b). "Lentinus edodes and Pleurotus species lignocellulolytic enzymes activity in submerged and solid-state fermentation of lignocellulosic wastes of different composition," Bioresource Technol. 99(3), 457462. DOI: 10.1016/j.biortech.2007.01.011

Ferraz, J. L. D. A., Souza, L., Fernandes, A. G. D., Oliveira, M. L. F., de Oliveira, J. R., and Franco, M. (2019). "Optimization of the solid-state fermentation conditions and characterization of xylanase produced by Penicillium roqueforti ATCC 10110 using yellow mombin residue (Spondias mombin L.)," Chem. Eng. Commun. 207(1), 31-42. DOI: $10.1080 / 00986445.2019 .1572000$

Filipe, D., Fernandes, H., Castro, C., Peres, H., Oliva-Teles, A., Belo, I., and Salgado, J. M. (2019). "Improved lignocellulolytic enzyme production and antioxidant extraction using solid-state fermentation of olive pomace mixed with winery waste," Biofuel. Bioprod. Bior. 14(1), 78-91. DOI: 10.1002/bbb.2073

Ghose, T. K. (1987). "Measurement of cellulase activities," Pure Appl. Chem. 59(2), 257268. DOI: $10.1351 /$ pac198759020257

Han, M. L., An, Q., Wu, X. J., Zheng, F., and Si, J. (2017). "Effects of different lignocellulose as inducers on laccase activities of Pleurotus ostreatus in submerged fermentation," Mycosystema 36(3), 349-357. DOI: 10.13346/j.mycosystema.160055

Han, M. L., Du, J., An, Q., and Li, C. S. (2018). "Effects of different culture substrate on 
laccase activities of Pleurotus ostreatus under different fermentation conditions," Mycosystema 37(8), 1100-1108. DOI: 10.13346/j.mycosystema.180064

Huang, L., Sun, N., Ban, L., Wang, Y., and Yang, H. P. (2019). "Ability of different edible fungi to degrade crop straw," AMB Express 9, 4. DOI: 10.1186/s13568-0180731-z

Janusz, G., Czuryło, A., Frąc, M., Rola, B., Sulej, J., Pawlik, A., Siwulski, M., and Rogalski, J. (2015). "Laccase production and metabolic diversity among Flammulina velutipes strains," World J. Microb. Biot. 31(1), 121-133. DOI: 10.1007/s11274-0141769-y

Kachlishvili, E., Penninckx, M. J., Tsiklauri, N., and Elisashvili, V. (2006). "Effect of nitrogen source on lignocellulolytic enzyme production by white-rot basidiomycetes under solid-state cultivation," World J. Microb. Biot. 22, 391-397. DOI: 10.1007/s11274-005-9046-8

Knežević, A., Milovanović, I., Stajić, M., Lončar, N., Brčeski, I., Vukojević, J., and Ćilerdžić, J. (2013). "Lignin degradation by selected fungal species," Bioresource Technol. 138, 117-123. DOI: 10.1016/j.biortech.2013.03.182

Lamia, M. H., Farid, Z., Sonia, M. A., Sevastianos, R., Samia, A., Véronique, D., and Mouloud, K. (2017). "Selective isolation and screening of actinobacteria strains producing lignocellulolytic enzymes using olive pomace as substrate," Iranian J. Biotechnol. 15(1), 74-77. DOI: 10.15171/ijb.1278

Leite, P., Silva, C., Salgado, J. M., Belo, I. (2019). "Simultaneous production of lignocellulolytic enzymes and extraction of antioxidant compounds by solid-state fermentation of agro-industrial wastes," Ind. Crop. Prod. 137, 315-322. DOI: 10.1016/j.indcrop.2019.04.044

Malherbe, S., and Cloete, T. E. (2002). "Lignocellulose biodegradation: fundamentals and applications," Rev. Environ. Sci. Bio. 1, 105-114. DOI: 10.1023/A:1020858910646

Membrillo, I., Sánchez, C., Meneses, M., Favela, E., and Loera, O. (2008). "Effect of substrate particle size and additional nitrogen source on production of lignocellulolytic enzymes by Pleurotus ostreatus strains," Bioresource Technol. 99(16), 7842-7847. DOI: 10.1016/j.biortech.2008.01.083

Metreveli, E., Kachlishvili, E., Singer, S. W., and Elisashvili, V. (2017). "Alteration of white-rot basidiomycetes cellulase and xylanase activities in the submerged cocultivation and optimization of enzyme production by Irpex lacteus and Schizophyllum commune," Bioresource Technol. 241, 652-660. DOI: 10.1016/j.biortech.2017.05.148

Nguyen, K. A., Kumla, J., Suwannarach, N., Penkhrue, W., and Lumyong, S. (2019). "Optimization of high endoglucanase yields production from polypore fungus, Microporus xanthopus strain KA038 under solid-state fermentation using green tea waste," Biol. Open 8(11), bio047183. DOI: 10.1242/bio.047183

Nguyen, K. A., Wikee, S., and Lumyong, S. (2018). "Brief review: lignocellulolytic enzymes from polypores for efficient utilization of biomass," Mycosphere 9(6), 10731088. DOI: $10.5943 /$ mycosphere/9/6/2

Oostra, J., Tramper, J., and Rinzema, A. (2000). "Model-based bioreactor selection for large-scale solid-state cultivation of Coniothyrium minitans spores on oats," Enzyme Microb. Tech. 27(9), 652-663. DOI: 10.1016/S0141-0229(00)00261-1

Pinar, O., Karaosmanoğlu, K., Sayar, N. A., Kula, C., Kazan, D., and Sayar, A. A. (2017). "Assessment of hazelnut husk as a lignocellulosic feedstock for the 
production of fermentable sugars and lignocellulolytic enzymes," 3 Biotech 7, 367. DOI: $10.1007 / \mathrm{s} 13205-017-1002-4$

Rajavat, A. S., Rai, S., Pandiyan, K., Kushwaha, P., Choudhary, P., Kumar, M., Chakdar, H., Singh, A., Karthikeyan, N., Bagul, S. Y., Agnihotri, A., and Saxena, A. K. (2020). "Sustainable use of the spent mushroom substrate of Pleurotus florida for production of lignocellulolytic enzymes," J. Basic Microb. 60(2), 173-184. DOI: 10.1002/jobm.201900382

Reddy, G. V., Babu, P. R., Komaraiah, P., Roy, K. R. R. M., and Kothari, I. L. (2003). "Utilization of banana waste for the production of lignolytic and cellulolytic enzymes by solid substrate fermentation using two Pleurotus species (P. ostreatus and $P$. sajor-caju)," Process Biochem. 38, 1457-1462. DOI: 10.1016/s0032-9592(03)00025-6

Sánchez, C. (2009). "Lignocellulosic residues: Biodegradation and bioconversion by fungi," Biotechnol. Adv. 27(2), 185-194. DOI: 10.1016/j.biotechadv.2008.11.001

Saparrat, M., Balatti, P. A., Martínez, M. J., and Jurado, M. (2010). "Differential regulation of laccase gene expression in Coriolopsis rigida LPSC No. 232," Fungal Biol. 114(11), 999-1006. DOI: 10.1016/j.funbio.2010.09.010

Saratale, G. D., Saratale, R. G., Ghodake, G. S., Jiang Y. Y., Chang, J. S., Shin, H. S., and Kumar, G. (2017). "Solid state fermentative lignocellulolytic enzymes production, characterization and its application in the saccharification of rice waste biomass for ethanol production: An integrated biotechnological approach," J. Taiwan Inst. Chem. E. 76, 51-58. DOI: 10.1016/j.jtice.2017.03.027

Sohail, M., Siddiqi, R., Ahmad, A., and Khan, S. A. (2009). "Cellulase production from Aspergillus niger MS82: effect of temperature and pH," New Biotechnol. 25(6), 437441. DOI: $10.1016 /$ j.nbt.2009.02.002

Stajić, M., Persky, L., Friesem, D., Hadar, Y., Wasser, S. P., Nevo, E., and Vukojević, J. (2006). "Effect of different carbon and nitrogen sources on laccase and peroxidases production by selected Pleurotus species," Enzyme Microb. Tech. 38(1), 65-73. DOI: 10.1016/j.enzmictec.2005.03.026

Sukumaran, R. K., Singhania, R. R., and Pandey, A. (2005). "Microbial cellulases production, applications and challenges," J. Sci. Ind. Res. India 64(11), 832-844. DOI: 10.1088/0960-1317/15/11/R01

Xie, C. L., Gong, W. B., Yan, L., Zhu, Z. H., Hu, Z. X., and Peng, Y. D. (2017). "Biodegradation of ramie stalk by Flammulina velutipes: mushroom production and substrate utilization," AMB Express 7, 171. DOI: 10.1186/s13568-017-0480-4

Zhang, Y. H. P., Himmel, M. E., and Mielenz, J. R. (2006). "Outlook for cellulase improvement: Screening and selection strategies," Biotechnol. Adv. 24(5), 452-481. DOI: 10.1016/j.biotechadv.2006.03.003

Zhang, Z. C., Li, J. S., Feng, F., Liu, D., Pang, Q. X., Li, M., and Chen, K. P. (2013). "Optimization of nutrition constituents for xylanase activity by Rhizopus stolonifer under solid-state fermentation on corncob," BioResources 8(2), 2018-2032. DOI: 10.15376/biores.8.2.2018-2032

Article submitted: March 3, 2020; Peer review completed: May 3, 2020; Revised version received: May 6, 2020; Accepted: May 7, 2020; Published: May 13, 2020.

DOI: $10.15376 /$ biores.15.3.4982-4995 